Rev.MVZ Córdoba 20(3):4675-4676, 2015. ISSN: 0122-0268

\title{
EDITORIAL
}

\section{Oropuche virus: A virus present but ignored}

\section{Virus de Oropuche: Un virus ignorado pero presente}

Bunyaviruses are RNA viruses that affect animals and plants; they have five genera and four of them affect humans: Orthobunyavirus, Nairovirus, Phlebovirus and Hantavirus. All of them are Arbovirus, except Hantavirus. The Orthobunyaviruses comprise Oropouche, Tahyna, La Crosse virus, California encephalitis virus and Heartland virus recently discovered (1). Except for Heartland virus which is transmitted by ticks of the genus Amblyoma, these Phleboviruses have as vectors mosquitoes, which bite small mammals which are able to be as reservoirs amplifiers.

The name of Oropouche virus came from the town of Oropuche Vegas, which is located on the island of Trinidad and Tobago, where it was detected in 1955 in a febrile patient and mosquitoes Coquilletidia venezuelenzis. Oropouche virus is prevalent in many parts of South America and the Caribbean. In the sylvatic cycle, the virus has several mosquitos vectors: Culicoides paraensis, Coquilletidia venezuelenzis and Aedes serratus. Wild mammals are bitten by these mosquitoes and viral loads are augmented, like in the sloth (Bradypus tridactiyus), primates (Aloutta sanguinus) and rodents among others. In the urban cycle, the vectors are Culicoides paraensis and Culex quinquefasciatus mosquitoes, both very common in tropical environments of Colombia (2).

Many outbreaks have been reported, especially in the Brazilian Amazon basin where Oropouche is the second cause of febrile syndrome, after dengue. In studies in febrile patients (Brazil), the fevers by arbovirus were caused as follow: dengue, alphavirus and Orthobunyavirus. Hemorrhagic arboviruses infections are clinically indistinguishable from Oropouche virus. Studies in Ecuador, Peru and Bolivia showed that between 2-6\% of patients with undifferentiated fever they had Oropuche infection (2). Symptoms Oropuche fever are similar to those of other viral tropical diseases such as Dengue, Chikungunya, Mayaro, Zika and other arboviruses. The clinical symptoms with rashes should be differentiated from other febrile as rubella, enterovirus rickettsia and leptospirosis (2).

Hernando Groot conducted perhaps the greatest study of sero-surveillance of arbovirus in Colombia between 1956 and 1962. Groot carried out neutralization tests and antibodies in monkeys and humans to Mayaro, Oropuche, Dengue, Ilhleus, Saint Louis, yellow fever, Venezuelan encephalitis, Eastern encephalitis, Bussuquara, Guaroa and Mayaro were found (3). Most Oropuche activity was
Los Bunyavirus son virus ARN que afectan animales y plantas; tienen cinco géneros y cuatro de ellos afectan a los humanos: Orthobunyavirus, Nairovirus, Phlebovirus y Hantavirus. Todos ellos son Arbovirus, excepto Hantavirus. Los Orthobunyavirus comprenden a Oropouche, Tahyna, La Crosse, virus de la encefalitis de California y el virus Heartland recientemente descubierto (1). A excepción del virus Heartland queestransmitido por garrapatas del género Amblyoma, estos Phlebovirus tienen como vectores a mosquitos, los cuales pican a pequeños mamíferos que a su vez son capaces de actuar como reservorios amplificadores.

El virus de Oropouche deriva su nombre de la localidad de Vegas de Oropuche, la cual se encuentra en la isla de Trinidad y Tobago, en donde fue detectado en 1955 en un paciente febril y en mosquitos Coquilletidia venezuelenzis. El virus de Oropouche es prevalente en muchas regiones de América del Sur y del Caribe. En el ciclo silvestre, el virus tiene varios mosquitos vectores: Culicoides paraensis, Coquilletidia venezuelenzis y Aedes serratus. Los mamíferos silvestres son picados por estos mosquitos y aumentan las viremias, como en el oso perezoso (Bradypus tridactiyus), primates (Aloutta sanguinus) y roedores entre otros. En el cido urbano los vectores son mosquitos Culicoides paraensis y Culex quinquefasciatus, ambos muy comunes en los ambientes tropicales de Colombia (2).

Muchos brotes epidémicos se han descrito, especialmente en la cuenca amazónica brasileña en donde Oropouchees la segunda causa de síndromes febriles, después del dengue. En estudios realizados en pacientes febriles (Brasil), la causa de fiebre por arbovirus fueron en su orden: dengue, alfavirus y orthobunyavirus. Las infecciones por arbovirus hemorrágicos son clínicamente indistinguibles de la del virus de Oropouche. Estudios realizados en Ecuador, Perú y Bolivia demostraron que entre el $2-6 \%$ de pacientes con fiebres indiferenciadas tenían infección por Oropuche (2). Los síntomas de la fiebre de Oropuche son similares a los de otras enfermedades tropicales virales como el Dengue, Chikungunya, Mayaro, Zika y otras arbovirosis. Loscuadros dínicos con exantemas deben diferenciarse de otros cuadros febriles como rubeola, enterovirus rickettsia y leptospira (2).

Hemando Groot llevó a cabo tal vez el mayor estudio de serovigilancia de arbovirus en Colombia entre 1956 y 1962. Él utilizó pruebas de neutralización y encontró en monos y humanos anticuerpos contra Mayaro, Oropuche, Dengue, Ilhleus, Sant Louis, fiebre amarilla, encefalitis venezolana, encefalitis del Este, Bussuquara, Guaroa y Mayaro (3). La mayor actividad para Oropuche fue detectada en monos del 
detected in monkeys from La Lizama village (Santander), while Mayaro and Bussuquara virus were detected in humans in the Peroles village (Santander). Interestingly, the Dengue virus had at that time a lower prevalence, 55 years later was demostrated the dynamics of the virus and the amazing adaptability of the vectors the cited study (3). Groot's work marked a milestone in the history of hemorrhagic viruses in Colombia and showed that surveillance must carry out actively looking for the viruses in the vectors, which would ensure the development and up-date of eco-epidemiology in Colombia.

After Groot's study, the Department of Defense US published in 1998 a work called Disease Vector Ecology Profile Colombia, which pointed out the importance of Oropuche and Mayaro virus among others (4).

Using a sera collection, a recent work in Colombia was carried out by National Institute of Health of Colombia and Secretary of Health of Cundinamarca state, the study was made within the frame of the National Program of Surveillance Febrile Syndromes and Dengue (5). In those sera that were collected between 2000 and 2001, researchers found antibodies to Oropuche and Mayaro viruses in Santander and Cundinamarca provinces.

Through this editorial we wish to point out that viruses are older than humans and they have adapted to versatile vectors that have allowed them to remain among humans and animals without being beated by antiviral drugs. But perhaps most important is without doubt that besides Oropuche virus, there are others viruses in Colombia that have infected us and we have not detected them. corregimiento de La Lizama (Santander), mientras que los virus Mayaro y Bussuquara fueron detectados en humanos en la localidad de Peroles(Santander). Curiosamente, el virus del Dengue en ese momento tuvo una menor prevalencia, lo que demuestra la dinámica de los virus y la sorprendente adaptabilidad de los vectores 55 años después del citado estudio (3). El estudio de Groot marcó un hito en la historia de los virus hemonágicos en Colombia y demostró que la vigilancia hay que llevarla a cabo de forma activa buscando los virus en los vectores, lo que garantizaría el desarrollo y actualización de la ecoepidemiología en Colombia.

Un tiempo después del estudio de Groot, el departamento de defensa de los EE.UU. publicó en 1998 un trabajo denominado Disease Vector Ecology Profile Colombia, el cual recalca la importancia del virus Oropuche y Mayaro entre otros (4).

A partir de un banco de sueros se llevo a cabo un trabajo reciente en Colombia por parte del Instituto Nacional de salud de Colombia y a la Secretaria de Salud Departamental deCundinamarca dentro del Programa Nacional de Vigilancia de Síndromes Febriles y Dengue pertenecientes (5). En esos sueros recolectados entre los años 2000 y 2001, los investigadores encontraron anticuerpos contra los virus Oropuche y Mayaro en los deparatementos de Santander y Cundinamarca.

Mediante este editorial deseamos remarcar que los virus son más viejos que los humanos y que se han adaptado a vectores versátiles que les han permitido mantenerse entre los humanos y los animales sin ser vencidos por fármacos antivirales. Pero tal vez, lo más importante es sin duda que además del virus Oropuche existen otros virus en Colombia que nos han infectado y no los hemos detectado.

\section{Salim Mattar V. Ph.D. Marco González T. M.Sc. \\ REFERENCES}

1. Bosco-Lauth AM, Panella N, Root Jj, Gidlewski $\mathrm{T}$, et al. Serological Investigation of Heartland Virus (Bunyaviridae: Phlebovirus) Exposure in Wild and Domestic Animals Adjacent to Human Case Sites in Missouri 2012-2013. Am J Trop Med Hyg 2015; 92(6):1163-7. doi:10.4269/ ajtmh.14-0702.

2. Mira BP, Andreotti R, Silva de AP, Cordeiro MA, Guerreiro RS, Oliveira CJ, et al. Detection of arboviruses of public health interest in free-living New World primates (Sapajus spp.;Alouatta caraya) captured in Mato Grosso do Sul, Brazil. Rev. Soc. Bras. Med. Trop 2013; 46(6): 684-690. http://dx.doi.org/10.1590/0037-8682-0181$\underline{2013}$

3. Groot H. Estudios sobre virus transmitidos por artrópodos, Rev Acad Colomb Cienc Ex Fis Nat 1964; 12(46):197-217.
4. Disease vector ecology profile Colombia. Armed Forces Pest Management Board, Defense Pest Management Information Analysis Center (DPMIAC); Washington, DC. [On line]. 1998. URL available: http://www.afpmb.org/sites/ default/files/pubs/dveps/COLOMBIA.PDF

5. Suárez R, Hidalgo M, Niño N, González C, Vesga J, Orejuela L, et al. Las rickettsias como agentes etiológicos de entidades febriles no diagnosticadas en Colombia. Ediciones Uniandes; Bogotá, DC. Colombia: 2008. URL Disponible en: http://publicacionesfaciso. uniandes.edu.co/sip/data/pdf/Las rickettsias como agentes etiologicos.pdf 